\title{
Reproductive behaviour of migrant women in Germany: Data, patterns and determinants
}

\author{
Susanne Schmid and Martin Kohls*
}

\begin{abstract}
This paper examines the fertility of female migrants in Germany. After introducing major hypotheses on migrant fertility we give an overview on German datasets that are available for migrant fertility research. Finally, descriptive and multivariate analyses based on the "Sample Survey of Selected Migrant Groups in Germany (RAM)" are presented. Migrant fertility in Germany differs according to the country of origin: among major migrant groups analysed, Turkish women show the highest and Polish women the lowest fertility level. Multivariate analysis shows that the existence of children born in the country of origin has a strong increasing effect on migrant fertility. Besides, migrant women with German partners have a lower fertility than women with non-German partners. Furthermore, the fertility of Muslim women is elevated when compared with other religious groups. In contrast, emotional ties with the country of origin and the level of native and German language skills show no influence on migrants' fertility.
\end{abstract}

\section{Introduction}

In recent decades female migration has gained in importance. At present, women constitute more than half of the migrant population worldwide. Their proportion might further rise as many developed ageing societies need a growing female labour force. Migration regularly occurs in women's active and childbearing age and therefore migrant fertility constitutes an important component in births and fertility rates in many developed countries. The following questions are frequently discussed: (1) to what extent the fertility pattern of their country of origin

\footnotetext{
* Susanne Schmid (author of correspondence), Sub-Division 22: Migration Research, Research Area II "International and Irregular Migration, Islam, Demography, Research Transfer", Federal Office for Migration and Refugees (BAMF), Frankenstrasse 210, D-90461 Nuremberg, Germany, Email: Susanne.schmid@bamf.bund.de

Martin Kohls, Sub-Division 22: Migration Research, Federal Office for Migration and Refugees (BAMF), Nuremberg, Germany.
} 
influences migrants' fertility behaviour after migration, (2) to what extent the migration as such influences the reproductive behaviour of migrants and (3) to what extent migrants adapt their reproductive intentions to the fertility level of the destination country.

Unavoidably, migrants are confronted with norms, attitudes and practices concerning fertility and childrearing prevailing in the destination country. In accordance with the geographical and cultural distance between the countries of origin and destination, reproductive attitudes and fertility levels will differ as well. As the fertility levels often reflect development stages of countries in inverse proportion, many female migrants come from the countries with higher fertility rates. For Europe and its 'post-industrial' societies with ageing and in some cases also declining populations the immigration of a younger population is of growing importance. Under the new demographic regime, where fertility had fallen to or below the replacement level, population increase or, at least, a stationary population regime can only be achieved by positive net migration. Debates on immigrations' role in ageing countries are by no means new (UN 2000). Practically all modern societies which have experienced the so-called "Second demographic transition" show much interest not only in immigration but also in the children and fertility of female migrants (Coleman 2006; Sobotka 2008).

This paper looks at the post-migratory reproductive behaviour of female migrants in Germany with respect to differentials by the country of origin and life events associated with the migratory movement and adaptation processes. In Germany the share of foreigners in the total population has grown continuously ever since 1961. At the end of 2008, around 6.7 million (8.2\%) persons with foreign nationality (of which 3.3 million women) were registered (German Federal Statistical Office 2009). The group of migrants and the persons of migrant origin ("Personen mit Migrationshintergrund") ${ }^{1}$ are considerably larger and comprise 15.4 million persons (of which 7.6 million women), i.e. $18.7 \%$ of the total population (German Federal Statistical Office 2008). In Germany, one-third of the population under the age of 5 already is of migrant origin. Hence, for Germany with fertility substantially below replacement level and an ongoing demographic ageing an increasing relevance of the migrant population is taken for granted (Dinkel 1990; Kohls 2007; Sobotka 2008). In spite of the high number of female migrants in Germany and significant fertility differences between German and migrant women, only very few analyses on the reproductive behaviour of female migrants are available. This might be partly explained by the lack of adequate data.

1 The term 'persons of migrant origin' "includes all persons who have migrated into the territory that constitutes today the Federal Republic of Germany since 1949 and all foreigners born in Germany as well as all German nationals born in Germany who have at least one parent who immigrated into Germany or who was born as a foreigner in Germany" (German Federal Ministry of the Interior 2008). 


\section{Theoretical considerations, Hypotheses and Databases}

Research on migrant fertility often deals with issues that can be addressed using official statistics, but that leaves many questions unanswered. More research is needed to gain insights into the 'inner fabric' of the post-migratory adaptation process which female migrants have to undergo. Questions to be raised are for example: To what extent does the migratory movement influence the reproductive behaviour of female migrants? Does it lead to postponing, bringing forward or suspending the desire for a(nother) child? Does it support maintenance of the norms of the country of origin concerning reproduction and family size when migrants are confronted with different norms and attitudes in the destination country? Do migrants undergo a gradual adaptation to the reproductive behaviour prevalent in the destination country? These questions have prompted different hypotheses for fertility research centred around migration and fertility.

\subsection{Hypotheses explaining the reproductive behaviour of female migrants}

Five broader hypotheses, elaborated in various contributions, constitute useful approaches to the study of migrants' fertility (see Goldstein and Goldstein 1981; Hervitz 1985; Kahn 1988, 1994; Young 1991; Stephen and Bean 1992; Lee and Pol 1993; Brockeroff and Yang 1994; Kulu 2005; Genereux 2007; Milewski 2007; Sobotka 2008). ${ }^{2}$

\section{Socialisation hypothesis}

The socialisation (or cultural) hypothesis states that migration does not affect fertility, because cultural values and norms acquired in the childhood in the country of origin will prevail as a determinant of the reproductive behaviour. Therefore, the fertility of first-generation migrants would remain similar to the childbearing behaviour in their country of origin (Goldberg 1959; Freedman and Slesinger 1961; Duncan 1965; Rosenwaike 1973; Stephen and Bean 1992; Kahn 1994).

\section{Selection hypothesis}

The selection hypothesis posits that migrants are a select group of people, whose reproductive behaviour is from the beginning more similar to the fertility prevalent in the country of destination than in the country of origin. According to this hypothesis fertility is not influenced by local, but by group-specific or individual characteristics covering education, occupation, career and family

\footnotetext{
These hypotheses are not mutually exclusive: they may operate at the same time, imposing counter-acting influences on migrant fertility, or they may apply only to some groups of migrants, or to specific time periods or spells of the migration and adaptation process.
} 
orientation (Myers and Morris 1966; Macisco et al. 1970; Hoem 1975; Goldstein and Goldstein 1981; Courgeau 1989; Michielin 2004; Kulu 2005).

\section{Interrelation hypothesis}

The interrelation (family formation) hypothesis argues that migration cannot be the sole reason for higher fertility levels upon arriving in the receiving country. It is more likely that different events, such as migration and family building, coincide with each other (Mulder and Wagner 1993; Singley and Landale 1998; Andersson 2004; Kulu 2005; Lindstrom and Giorguli-Saucedo 2007).

\section{Disruption hypothesis}

The disruption hypothesis suggests that migration always means a break in the life history of a person and causes a delay of childbearing. As a result, migration lowers fertility before and upon arrival in the receiving country. But this fertility decrease is only temporary and does not influence the completed fertility of a woman (Goldstein 1973; Carlson 1985; White et al. 1995; Brockeroff 1995; Abbasi-Shavazi and McDonald 2002).

\section{Adaptation hypothesis}

The adaptation hypothesis assumes that the current socio-economic conditions and the cultural norms in the destination country will soon exert a strong influence on migrants' childbearing behaviour and overcome traditional attitudes left behind in the country of origin (Farber and Lee 1984; Brockeroff and Yang 1994; Courgeau 1989; Kulu 2005; Genereux 2007; Milewski 2008).

These migrant fertility hypotheses contain assumptions about the causes of migration and the post-migratory adaptation as well as inner (personal) factors and outer (socio-economic) circumstances. Based on these hypotheses, the major influences on migrant fertility are the following:

1. Socialisation experiences in the country of origin (socialisation hypothesis)

2. Individual or group-specific family orientation and/or achievement motivation (selection hypothesis)

3. Motivation for migration (interrelation hypothesis)

4. Circumstances of the migration process (disruption hypothesis)

5. Experiences in the destination country which increase with the length of stay (adaptation hypothesis)

To sum up, it is taken for granted that migration will alter the reproductive behaviour as both the outer (objective) frame of decision-making for reproduction and the personal (subjective) situation in which a reproductive decision will be made have changed thoroughly (Nauck 1987; Milewski 2007; Sobotka 2008). 


\subsection{Databases}

Deficits in the current research on migrant fertility in Germany are mainly due to unsatisfying or missing databases. Previous studies exclusively based on official statistics have shown errors, especially regarding migrant populations (Kohls 2008; Peuckert 2008; Schmid and Kohls 2008, 2009). Apart from the official statistics, there are further databases from administration and registers as well as from social science surveys, which are suitable for migrant fertility analyses in Germany.

\subsubsection{Administration and register data}

Many databases are assembled from administrative statistics or register data collected for a specific purpose and stipulated by the law (e.g. census act, population statistics act). Furthermore, databases can also result from data being collected for other reasons. In the Statutory Pension Insurance, for example, many data are collected to calculate the pension expenditures, for instance data on parental leaves. ${ }^{3}$ Databases from civil administration and registers constitute complete samples with a large number of cases, which makes them very costintensive. Therefore, the parameters which could be drawn out of these databases are very limited and are mostly apt to serve legal purposes only.

\section{Official statistics}

The official birth statistics constitutes an important data source for immigrant fertility analysis in Germany. ${ }^{4}$ Since 1970 births are registered by the mother's nationality. ${ }^{5}$ However, only births which took place in Germany by women who are registered in the local population register are included. Nevertheless, this database is commonly used for analyses of migrant fertility in Germany, because it allows examining its trends over time (see Kane 1986; Mammey 1990; Schwarz 1996; Mammey and Schwarz 2002).

\section{Microcensus}

The Microcensus provides official representative statistics of the German population (former Federal Republic of Germany since 1957 and the New Laender, i.e. the former German Democratic Republic, since 1991). ${ }^{6}$ Apart from socio-demographic and labour statistics, data on births are collected. In 2005 an innovative questionnaire has been introduced, which permits analyses of persons

\footnotetext{
Credited time ("Anrechnungszeit") due to childrearing.

These data can be used for research, see www.forschungsdatenzentrum.de.

Naturalised women are included as German women in the official birth statistics.

6 These data can be used for research as well, see www.forschungsdatenzentrum.de.
} 
of migrant origin (German Federal Statistical Office 2008). ${ }^{7}$ Unfortunately, fertility analyses based on the Microcensus were systematically distorted until recently, because it only asked about the number of births within the current marriage. For fertility analyses, however, the complete number of births of a woman, independent of the marital status, is required. With the revision of the Microcensus act in 2007 this data deficit has been corrected. ${ }^{8}$

Statutory Pension Insurance (Gesetzliche Rentenversicherung, GRV)

As Germany has an 'unfunded' pension system ('pay-as-you-go' system) a Statutory Pension Insurance disposes of data on all relevant characteristics (e.g. age, sex, nationality, parental leave). Thus, migrant fertility analyses can be based on these data (Kreyenfeld and Mika 2006; Schmid and Kohls 2008). ${ }^{9}$ The GRV databases show a high validity because the registration status constitutes pension claims in later life (Scholz 2005). Status changes, e.g. birth, death, immigration, emigration or unemployment are thereby exactly documented. A disadvantage of the database is that the persons registered in the GRV do not represent the whole German population because certain groups such as civil servants, self-employed or also housewives ${ }^{10}$ are not included. The sample covers $95 \%$ of the Germans' births and $84 \%$ of the foreigners' births, but only $79 \%$ of the German and $67 \%$ of the foreign women population aged 15 to 45 are considered (Schmid and Kohls 2009).

Central Register of Foreigners (Ausländerzentralregister, AZR)

All foreigners officially registered in Germany are recorded in the Central Register of Foreigners, which includes information about age, sex, nationality, date of immigration and registration status. ${ }^{11}$ Births are taken into consideration in the AZR, but cannot be attributed to their parents. Therefore migrant fertility analyses are not possible with this dataset.

\subsubsection{Data from social-science surveys}

In addition to administrative and register databases which are collected to meet the official requirements, there are numerous scientific datasets. Data from socialscience surveys are usually characterised by restricted sample size. Nevertheless, their major benefit lies in the richness of variables included. The main surveys will be presented below.

See Footnote 1.

Data of the revised Microcensus 2008 are not available yet.

These data can be used for research: www.fdz-rv.de.

Housewives are included but tend to register not immediately after birth but years after because their right to a pension can not expire and will be invoked later in life.

11 These data cannot be used for specific research, but the most important results are published annually, see German Federal Statistical Office 2009. 
German Socioeconomic Panel (GSOEP)

The German Socioeconomic Panel, a survey started in 1984, is one of the most important databases in social research in Germany. ${ }^{12}$ The panel is designed as a longitudinal questionnaire in private households. In 2006, GSOEP had registered 1,494 persons of foreign nationality. Migrant fertility analyses can be undertaken with SOEP (see Nauck 1987, 1988; Mayer and Riphahn 2000; Milewski 2007). Because of the restricted number of respondents, the sample might not be representative for all migrant women in Germany.

\section{Generations and Gender Survey (GGS)}

In the first part of the Generations and Gender Survey (GGS) approximately 5\% of the interviewed persons had a non-German nationality (see Ruckdeschel et al. 2006). This survey was designed as a follow-up to the Family and Fertility Survey, carried out first in 1992. On account of the inadequate migrant sample an additional sample of approximately 4,000 Turkish individuals was drawn in 2006 (see Ette et al. 2007). Altogether, migrant fertility analyses of the greatest migrant groups in Germany will be possible based on GGS. But no analyses regarding this aspect have been conducted until now.

Sample Survey of Selected Migrant Groups in Germany (Repräsentativbefragung ausgewählter Migrantengruppen in Deutschland, RAM)

The Sample Survey of Selected Migrant Groups in Germany (RAM) was carried out in 2006/2007 by order of the Federal Office for Migration and Refugees (BAMF). Respondents were persons of Turkish, Greek, Italian, Polish and former Yugoslavian origin (see Babka von Gostomski 2008; Babka von Gostomski and Pupeter 2008). Analyses of migrant fertility can be conducted based on the RAM survey. It included only persons who were registered in the Central Register of Foreigners by 30 June 2006, had one or more foreign citizenship(s) and had lived in Germany for more than 12 months. Thus "foreigners" are in the focus of the analysis and not the "persons of migrant origin". The RAM results are presented in Chapter 3.

\subsection{Research on migrant fertility in Germany - an overview}

A number of studies using official birth statistics found out that the fertility of foreign women was persistently higher than that of German women since 1970. However, since the 1990s, the period fertility rates of foreign women have declined below the replacement level, while sub-replacement fertility has been experienced among German women already for several decades (Schulz 1978; Schwarz 1980, 1996; Kane 1986; Nauck 1987, 1988; Höhn et al. 1990; Mammey 1990; Schoorl 1995; Roloff 1997; Mammey and Schwarz 2002; Schmid and Kohls 2008, 2009). Table 1 shows that the number of births among German

12 These data can be used for research, more information see: www.diw.de/soep. 
women fell sharply between 1970 and 1975 to stabilise until 1985 . With regard to foreign women, the data show a different trend. The number of births doubled from 1970 to 1975 and then dropped until 1985. After 1985, the number of births rose up to 125,000 in 2000 to decrease again to about 109,000 births in 2006 .

A most common period fertility measure for comparisons between population groups is the period Total Fertility Rate (TFR). In 1975, the TFR of German women was at 1.3 children per woman, and that of foreign women at 2.7 children per woman. After a decrease until 1985, the TFR stabilised till 2006 at 1.3 children per German woman and at 1.7 children per foreign woman (Table 1). The difference between German and foreign women declined between 1990 and 2006 from 0.8 to 0.4 (Table 1$){ }^{13}$

Table 1:

Live births and period TFR of German and foreign women*, official statistics, 1970$2006 * *$

\begin{tabular}{lrrrrrrrrr}
\hline & $\mathbf{1 9 7 0}$ & $\mathbf{1 9 7 5}$ & $\mathbf{1 9 8 0}$ & $\mathbf{1 9 8 5}$ & $\mathbf{1 9 9 0}$ & $\mathbf{1 9 9 5}$ & $\mathbf{2 0 0 0}$ & $\mathbf{2 0 0 5}$ & $\mathbf{2 0 0 6}$ \\
\hline Live Births, $\mathbf{B}_{\mathbf{t}}$ & & & & & & & & \\
Germans & 754,028 & 493,690 & 527,481 & 520,753 & 625,116 & 561,044 & 530,970 & 449,518 & 438,151 \\
Foreigners & 56,658 & 106,708 & 93,051 & 65,312 & 101,969 & 120,237 & 124,701 & 110,504 & 108,540 \\
\hline \multicolumn{2}{l}{ Total Fertility Rate, } & $\mathbf{T F R}$ per woman & & & & & & \\
Germans & 2.00 & 1.34 & 1.37 & 1.25 & 1.37 & 1.24 & 1.33 & 1.30 & 1.29 \\
Foreigners & 2.11 & 2.65 & 2.36 & 1.67 & 2.18 & 1.81 & 1.87 & 1.69 & 1.66 \\
Difference & 0.11 & 1.31 & 0.99 & 0.42 & 0.81 & 0.57 & 0.54 & 0.39 & 0.37 \\
\hline
\end{tabular}

Note: *Births by mothers' nationality.

**1970-2000: former Federal Republic of Germany (Old Laender). 2001-2006: former Federal Republic of Germany (Old Laender) without Berlin.

Source: Authors' calculations based on data of the German Federal Statistical Office.

However, Schmid and Kohls (2008) found out that the official statistics provide a migrant fertility that is lower than in reality. The bias results from an inclusion of women in the analyses who are not 'at risk' to bear a child in Germany because they already emigrated. When taking into account the more valid population stock of the Central Register of Foreigners (AZR), foreign women realised a 7-8\% higher TFR (Schmid and Kohls 2008).

Migrant fertility analyses with the German Socio-Economic Panel showed clearly that foreign women have lowered their fertility continuously since 1970 according to their migration history, their stage of integration and their educational level (Nauck 1987, 1988; Mayer and Riphahn 2000; Milewski 2007). Intergenerational analyses showed that migrants of the second generation have a

13 Naturalised women (Germans of migrant origin) are included as German women in the dataset. 
lower fertility level than first-generation migrants (Nauck 2007; Milewski 2007, 2008).

Furthermore Kreyenfeld and Mika (2006) and Schmid and Kohls (2009) analysed the fertility of German and non-German women using data from the Statutory Pension Insurance (GRV) and found out that there are great differences between migrant groups. On the one hand, high fertility prevailed among migrant women coming from Africa, Turkey and Asia, and, on the other hand, a lower fertility was typical of women coming from the countries to the west of Germany ${ }^{14}$ and from southern Europe ${ }^{15}$ (Schmid and Kohls 2009).

Other research on specific migrant groups observed that migrant women from higher-fertility countries do not keep the higher fertility level of their country of origin. For instance, for Italians coming to Germany in the 1960s and 1970s the adaptation process was responsible for that (Schulz 1978), while for the fertility decline among ethnic Germans from the former Soviet Union the tempo effects, i.e. the postponement of births, play an additional role (Dinkel and Lebok 1997). In comparison, Turkish migrants in Germany show a higher fertility than native Germans, which, however, decreased continuously to a level below that of their country of origin (Schwarz 1980, 1996; Kane 1986; Nauck 1987, 1988; Höhn et. al 1990; Schoorl 1995; Schwarz 1996; Haug 2002).

\section{Migrant fertility in Germany - Analyses based on data of the Sample Survey of Selected Migrant Groups in Germany (RAM)}

The Sample Survey of Selected Migrant Groups in Germany 2006/2007 (RAM) is used in our research to analyse different factors influencing the reproductive behaviour of migrant women.

\subsection{Data and method}

The representative Sample Survey of Selected Migrant Groups in Germany (RAM) was conducted in 2006/2007 on behalf of the Federal Office for Migration and Refugees (BAMF). It comprises 4,576 respondents including 2,233 women. The allocation of the sample by nationalities presents the following shares (Babka von Gostomski 2008): 33.0\% Turkish women (total number: 738), 21.2\% Former Yugoslavian women (473), 18.7\% Polish women (418), 13.8\% Greek women (309), 13.2\% Italian women (295). The response rate reached over $40 \%$ which is similar to other social surveys. The number of answered questions was very high (Babka von Gostomski and Pupeter 2008).

14 Belgium, Denmark, France, Luxembourg, the Netherlands, Austria, Switzerland.

15 Greece, Italy, Portugal, Spain. 
Our analysis focuses on the Completed Fertility Rate (CFR), which represents the number of children per woman in the cohorts of women reaching the end of their childbearing years. All women born after 1966, i.e. aged below 40 at the time of the survey, were excluded from analysis, leaving a sample of 958 migrant women.

First, we present a descriptive analysis of migrant fertility. Then, multivariate analysis in Section 3.3 features different multiple regressions models, with the "number of children" being explained by variables that are included in the model stepwise or blockwise.

\subsection{Descriptive analyses}

Fertility of migrant women varies widely by their country of origin. Among the five migrant groups analysed, women over age 40 coming from Turkey have, with 3.5 children per woman, the highest fertility (Table 2 ). In contrast, women born in Poland have the lowest CFR with 1.5 children per woman. Furthermore, Turkish women show a pronounced decline in their CFR: those born before 1940 had on average 4.2 births per woman, whereas Turkish migrants born between 1961 and 1965 had fewer than 3 children per woman, which means a reduction of about $30 \%$ (Table 2). This development corresponds approximately to the observed fertility decline in Turkey. Other migrant groups show lower fertility levels in all cohorts. In sum the younger the birth cohort, the lower the CFR values. Only in the cohorts of 1951-1960 Italian, Greek and Polish women show a slightly higher fertility than their older counterparts born in 1941-1950 (see Table 2). In comparison to German women, who had a CFR of about 2 children per woman in the cohorts of 1934-1944 (Kreyenfeld and Mika 2006), only Polish women achieved a lower fertility.

Especially the older birth cohorts realised most of their births in the country of origin. Among the cohorts of 1940 and older between 51\% (Greece, Italy) and $89 \%$ (Poland) of their children were born in the country of origin. Cohorts born in $1961-1965$ realised only $16.7 \%$ (Turkey) to $62.7 \%$ (Poland) of their births in the country of origin, with these shares depending strongly on age at migration and the length of stay (Table 2).

The distribution of the number of children shows that $75 \%$ of the Turkish women have 3 or more children. Other migrant groups have much lower shares of women with 3 or more children and the highest proportions of women with 2 children. Childlessness is very unusual for Turkish women $(3.7 \%)$ but more frequent for Polish women (12.9\%, Table 2). In comparison, 13\% (Kreyenfeld and Mika 2006) to 14\% (German Federal Statistical Office 2007) of German women born between 1931 and 1951 remained childless. 
Table 2:

Completed Fertility Rate (CFR) of migrants" by cohorts, country of origin and number of children, per woman

\begin{tabular}{lccccc}
\hline Country of origin & Turkey & $\begin{array}{c}\text { Former } \\
\text { Yugoslavia }\end{array}$ & Italy & Greece & Poland \\
\hline CFR per woman & 3.47 & 2.09 & 2.27 & 2.07 & 1.53 \\
Total number (unweighted) & 286 & 222 & 144 & 158 & 148 \\
Birth cohort & & & & & \\
1940 and older & 4.22 & 2.64 & 2.50 & 2.21 & $(1.78)$ \\
$1941-1950$ & 3.70 & 2.13 & 2.38 & 1.93 & 1.45 \\
1951-1960 & 3.17 & 1.97 & 2.46 & 2.12 & 1.61 \\
1961-1965 & 2.92 & 1.77 & 1.79 & 2.08 & 1.38 \\
Children born in the country of origin & & & & \\
1940 and older & 3.23 & 2.04 & 1.38 & 1.11 & $(1.58)$ \\
1941-1950 & 2.27 & 1.24 & 0.51 & 0.75 & 1.23 \\
1951-1960 & 1.08 & 0.86 & 0.45 & 0.74 & 1.05 \\
1961-1965 & 0.49 & 0.86 & 0.47 & 1.05 & 0.87 \\
Distribution of the number of children (in \%) & & & & \\
No children & 3.7 & 10.3 & 7.6 & 7.7 & 12.9 \\
1 child & 4.5 & 22.4 & 9.9 & 15.4 & 35.7 \\
2 children & 17.1 & 42.6 & 42.7 & 46.2 & 38.6 \\
3 children & 30.0 & 12.2 & 28.2 & 25.3 & 10.0 \\
4 and more children & 44.8 & 12.5 & 11.5 & 5.5 & 2.9 \\
\hline
\end{tabular}

Note: *Only women over age 40 are considered; in total, 958 respondents were included.

Source: Authors' calculations based on RAM 2006/2007, unweighted, sample. Numbers are in brackets if less than 10 persons were included in the sample (unweighted).

Considering various factors affecting fertility behaviour, we assume that having a German partner promotes the adaptation process of migrant women as it offers more opportunities of regular contact with native Germans. This hypothesis is supported by descriptive analysis for all migrant groups except Polish women (Table 3). The strongest influence can be observed for women from former Yugoslavia, whose CFR is by $38 \%$ lower when having a German partner. Only for Polish women this relationship runs in the opposite direction and their fertility lies above average when having a German partner. Arguably, most of the Polish migrants living in partnerships with Germans have migrated to Germany for marriage and family formation and were therefore more family-orientated than the other Polish migrants (Nauck 2007). This finding gives some support on one side to the dominance of individual characteristics like family orientation (selection hypothesis) and, on the other side, the family-formation hypothesis of migration (interrelation hypothesis). 
Table 3:

Completed Fertility Rate (CFR) of migrants* by different factors influencing their fertility behaviour by country of origin, per woman

\begin{tabular}{|c|c|c|c|c|c|}
\hline Country of origin & Turkey & $\begin{array}{c}\text { Former } \\
\text { Yugoslavia }\end{array}$ & Italy & Greece & Poland \\
\hline \multicolumn{6}{|c|}{ Nationality / nationality of the partner $(n=748)$} \\
\hline Non-German / German & 3.07 & 1.42 & 1.79 & 1.92 & 1.54 \\
\hline Proportion of all couples & $6.1 \%$ & $18.9 \%$ & $17.2 \%$ & $13.3 \%$ & $64.2 \%$ \\
\hline Non-German / non-German & 3.49 & 2.26 & 2.50 & 2.12 & 1.47 \\
\hline Proportion of all couples & $93.9 \%$ & $81.1 \%$ & $82.8 \%$ & $86.7 \%$ & $35.8 \%$ \\
\hline \multicolumn{6}{|c|}{ School attendance in years $(n=900)$} \\
\hline Less than 9 years & 3.36 & 2.25 & 2.54 & 2.05 & 1.85 \\
\hline $9-12$ years & 2.71 & 1.54 & 1.77 & 2.24 & 1.43 \\
\hline More than 12 years & n.a. & 1.69 & 1.67 & $(1.54)$ & 1.52 \\
\hline \multicolumn{6}{|c|}{ Training qualification $(n=937)$} \\
\hline No training qualification & 3.51 & 2.26 & 2.38 & 2.14 & 1.47 \\
\hline Completed apprenticeship & 2.94 & 1.58 & 1.95 & 1.65 & 1.67 \\
\hline Other, higher qualification & n.a. & 1.68 & 1.46 & 1.73 & 1.53 \\
\hline \multicolumn{6}{|l|}{ Religious affiliation $(n=947)$} \\
\hline Catholic & n.a. & 1.71 & 2.18 & $(2.73)$ & 1.54 \\
\hline Christian Orthodox & n.a. & 2.10 & n.a. & 2.04 & n.a. \\
\hline Muslim & 3.49 & 3.09 & n.a. & $(2.35)$ & n.a. \\
\hline Others, none & 3.43 & 1.44 & 3.19 & n.a. & 1.51 \\
\hline \multicolumn{6}{|c|}{ Religiosity (Self-evaluation) ( $\mathrm{n}=955)$} \\
\hline Religious, very religious & 3.57 & 2.17 & 2.22 & 2.09 & 1.57 \\
\hline Neutral & 3.43 & 2.05 & 2.26 & 2.14 & 1.38 \\
\hline Little, not religious & 2.54 & 1.90 & 2.56 & 1.89 & 1.62 \\
\hline \multicolumn{6}{|c|}{ Emotional ties to the country of origin $(n=958)$} \\
\hline Very strong & $3.50^{\circ}$ & 1.98 & 2.23 & 2.16 & 1.49 \\
\hline Strong & 3.81 & 2.06 & 2.15 & 2.06 & 1.48 \\
\hline Neutral & 2.99 & 2.19 & 2.27 & 2.05 & 1.64 \\
\hline Little, not at all & 3.58 & 2.17 & 2.68 & 1.79 & 1.55 \\
\hline \multicolumn{6}{|c|}{ Emotional ties to the destination country $(n=961)$} \\
\hline Very strong & 2.75 & 2.06 & 1.68 & 1.59 & 1.32 \\
\hline Strong & 3.08 & 2.05 & 2.06 & 1.68 & 1.44 \\
\hline Neutral & 3.12 & 1.63 & 2.42 & 1.79 & 1.18 \\
\hline Little, not at all & 3.72 & $(1.71)$ & $(1.77)$ & $(1.15)$ & $(2.14)$ \\
\hline \multicolumn{6}{|c|}{ Native language skills $(\mathrm{n}=958)$} \\
\hline Very good & 3.23 & 1.95 & 2.22 & 2.08 & 1.47 \\
\hline Good & 3.28 & 2.38 & 2.65 & 2.14 & 2.21 \\
\hline Medium, not at all & 4.33 & 2.42 & $(1.44)$ & 1.72 & n.a. \\
\hline \multicolumn{6}{|c|}{ German language skills $(\mathrm{n}=958)$} \\
\hline Very good & 2.39 & 1.84 & 1.66 & 1.70 & 1.55 \\
\hline Good & 3.13 & 1.94 & 2.51 & 2.12 & 1.46 \\
\hline Medium, not at all & 3.66 & 2.47 & 2.54 & 2.17 & 1.59 \\
\hline
\end{tabular}

Note: *Only women over age 40 are considered.

Source: Authors' calculations based on RAM 2006/2007, unweighted, sample. Numbers are in brackets if less than 10 persons were included in the sample (unweighted). 
Other socio-economic factors such as educational level and income also affect the completed fertility of migrants. Depending on the level of schooling and professional training, personal career orientation could compete with family orientation. Especially western Germany displays a typical fertility pattern which reflects this conflict: higher educated women frequently remain childless and have, on average, fewer children than the less educated women (Kreyenfeld 2004; Konietzka and Kreyenfeld 2007; German Statistical Office 2007). Table 3 indicates that the educational level (years of school attendance) has a strong impact on the completed fertility of migrant women. The highest completed fertility ( 3.4 children per woman) is achieved by Turkish women with fewer than 9 years of school attendance (Table 3). Women from former Yugoslavia and Poland with more than 12 years schooling show a slightly higher fertility than those with 9-12 years of schooling. Women from East Germany show the same connection, i.e. higher educated women have higher fertility than women with medium education level (Klein and Lauterbach 1994; Huinink 1995).

The reproductive behaviour can also be influenced by religious affiliation and (subjective) religiosity of a person (Westoff and Frejka 2007). Most migrant populations in Germany have the same religious affiliation that is dominant in their country of origin. The vast majority of Turkish immigrants are Muslims, Catholicism is typical of most Italian and Polish women, and most Greeks and eastern Europeans belong to Orthodox Christianity. Women from former Yugoslavia show heterogeneous affiliations, which corresponds to the realities of multi-ethnic Yugoslavia. Muslims of Turkish origin have, with 3.5 children per woman, the highest CFR (Table 3). Muslim women from former Yugoslavia also have an above-average fertility of 3.1 children per woman as compared with the CFR of 1.7 among the Catholic and 2.1 among Christian Orthodox women from that region.

Since affiliation may be more a cultural marker of identity than a sign of religious sentiments, self-declared religiosity was also included in the RAM survey. Women who evaluated themselves as being religious or very religious show a higher CFR than those admitting to looser religious bonds. Women from former Yugoslavia and Turkey show this link most clearly (Table 3).

In the course of adapting to the socio-economic structures and living conditions in the destination country the reproductive norms and values of migrant women are likely to be affected. The integration level is also mirrored in migrants' fertility behaviour (Nauck 1988, 2007). The degree of intensity with which migrants stick to the cultural traditions of their country of origin may serve as an important indication of their integration level. At the same time, many migrants may increasingly identify themselves with the norms and living conditions of their destination country. The feelings in both directions clash with each other but, in an ideal type of adaptation process, a shift from the former to the latter would be expected (Esser 1980). The continuation of a strong attachment to cultural norms of the country of origin may also signal lasting 
obedience to the corresponding norms of family formation and family size. Growing emotional ties with the country of destination symbolise a degree of contentment with the post-migratory situation and a willingness to adapt to the prevailing attitudes toward reproductive behaviour and family size in the destination country. Table 3 indicates that the emotional ties to the country of origin have no measurable effect on migrant fertility, but the emotional attachment to the destination country shows a connection: The higher the emotional ties to Germany, the lower the CFR on average. Probably women strongly related to Germany are more integrated and thus also more adapted to the prevailing low-fertility norms and values in Germany. This result corresponds with other studies (Nauck 1988, 1993, 2007).

Native language skills have no association with migrant fertility, but good German language skills, however, are linked to lower migrant fertility (Table 3). Turkish migrants with "very good" German language skills show, with 2.4 births per woman, a CFR by 35\% lower than Turkish migrants with "poor" or "medium" German language skills. This trend can also be observed for other migrants except those from Poland.

\subsection{Multivariate analyses}

Regression models are useful for identifying the most important factors influencing migrants' fertility when other relevant factors are controlled for. At first, several blocks of influence factors are block- or stepwise included in the multiple regression models (Model 1-5). Afterwards, a final model including all relevant parameters is calculated for all migrants together (Model 6 in Table 4) and for individual migrant groups (Table 4).

The reference Model 1 confirms the descriptive analyses concerning fertility levels, i.e. the highest fertility of Turkish women and the higher fertility of the older cohorts. By keeping the "cohort" and the "nationality" under control, the "length of stay" has no effect on the number of children among female migrants (Table 4). In subsequent models, "nationality", "birth cohorts" as well as the "length of stay" are controlled. Then additional blocks of factors are added.

In Model 2 two variables are added: "children born in the country of origin" increase the completed fertility of migrants significantly, while the existence of a German partner has a negative effect on fertility. This confirms results obtained in the descriptive analyses. In contrast, the independent influence of the birth cohort has largely disappeared due to the fact that the parameters "cohort" and "children born in the country of origin" are closely interrelated.

In Model 3, previous variables are replaced by educational characteristics. Especially a lower educational degree (measured by the years of school attendance) and low professional qualification increase the probability of having more children. These variables have an independent influence on fertility, in 
addition to the effects of nationality, birth cohort and the length of stay in the country (Table 4).

Model 4 includes religious affiliation; especially Muslims are more likely to have more children, compared to the reference group of Catholics. Furthermore, self-declared religiosity is also linked to a higher fertility. When including affiliation in the model, the effect of nationality largely disappears for Turks and for women from former Yugoslavia. Clearly, these two parameters are interdependent.

In Model 5, indicators estimating the degree of personal identification with the origin and destination country are included. Especially (very) good German language skills signal a large degree of incorporation into the receiving society and high likelihood of upward social mobility. Model 5 showed that emotional ties to the country of origin and the country of destination have no impact on migrants' fertility. In contrast, weaker language skills (both of the country of origin and of destination) tend to result in a higher fertility level (Table 4).

All the parameters are combined in the final Model 6. The number of children born in the country of origin and being a Muslim have a considerable effect on migrants' fertility. Nationality shows no significant impact for women from Turkey and former Yugoslavia, a clear positive effect is shown only for Italian women. The decreasing effect of the existence of a German partner and the positive effect of low educational level on fertility are confirmed in Model 6. Both parameters lost their significance, however, due to an inclusion of many control variables. Self-reported religiosity has no measurable effect, whereas Muslim affiliation shows a strong positive effect. Emotional ties to the country of origin and destination and the language skills no longer show any significant effect. When using a stepwise multiple regression model the results remain unchanged (not shown here).

The higher share of Turks in the survey may suppress the influences of other migrant groups when all migrants are analysed together. Therefore, additional multiple regression models were calculated for each migrant group (Table 5). The analyses showed that the existence of children born in the country of origin has a strong effect on fertility in each migrant group. Among women from former Yugoslavia, Muslims have considerably higher fertility than the reference group of Catholics. The fertility-decreasing effect of living with a German partner could be confirmed only for women from former Yugoslavia and Greece. Polish women show an opposite trend, which confirms the results of the descriptive analyses. The educational level shows, like the degree of religiosity, no effect on the fertility of individual migrant groups. Identity characteristics like emotional ties to the country of origin or growing feelings of belonging to the destination country show some measurable effect only for women from former Yugoslavia. ${ }^{16}$

16 Thus, strong emotional ties to Germany tend to increase the fertility of women from former Yugoslavia and strong emotional ties to their country of origin tend to decrease it (not significant). 
Table 4:

Fertility of migrant women* in Germany, results from a multiple regression model (block-wise)

\begin{tabular}{|c|c|c|c|c|c|c|c|c|c|c|c|c|}
\hline & \multicolumn{2}{|c|}{ Model 1} & \multicolumn{2}{|c|}{ Model 2} & \multicolumn{2}{|c|}{ Model 3} & \multicolumn{2}{|c|}{ Model 4} & \multicolumn{2}{|c|}{ Model 5} & \multicolumn{2}{|c|}{ Model 6} \\
\hline & Beta & Sig. & Beta & Sig. & Beta & Sig. & Beta & Sig. & Beta & Sig. & Beta & Sig. \\
\hline \multicolumn{13}{|c|}{ Nationality (Ref.: Poland) } \\
\hline Turkey & 0.60 & $* * *$ & 0.52 & $* * *$ & 0.47 & $* * *$ & 0.15 & & 0.48 & $* * *$ & 0.07 & \\
\hline Former Yug. & 0.18 & $* *$ & 0.12 & + & 0.11 & & 0.04 & & 0.14 & $*$ & -0.05 & \\
\hline Italy & 0.20 & $* * *$ & 0.21 & $* * *$ & 0.17 & $* *$ & 0.17 & $* *$ & 0.17 & $* *$ & 0.16 & * \\
\hline Greece & 0.12 & $*$ & 0.10 & $*$ & 0.09 & + & 0.03 & & 0.07 & & 0.01 & \\
\hline \multicolumn{13}{|c|}{ Birth Cohort (Ref.: 1940 and older) } \\
\hline $1941-1950$ & -0.12 & $* *$ & 0.03 & & -0.03 & & -0.11 & $* *$ & -0.07 & + & 0.07 & \\
\hline $1951-1960$ & -0.22 & $* * *$ & -0.01 & & -0.12 & $*$ & -0.21 & $* * *$ & -0.16 & $* *$ & 0.04 & \\
\hline $1961-1965$ & -0.29 & $* * *$ & -0.03 & & -0.18 & $* *$ & -0.28 & $* * *$ & -0.21 & $* * *$ & 0.04 & $*$ \\
\hline \multicolumn{13}{|c|}{ Length of stay (Ref.: Less than 10 years) } \\
\hline $10-20$ years & 0.04 & & 0.04 & & 0.01 & & 0.04 & & 0.05 & & 0.02 & \\
\hline $20-30$ years & 0.01 & & 0.13 & + & 0.02 & & 0.04 & & 0.04 & & 0.16 & * \\
\hline$>30$ years & -0.11 & & 0.12 & & -0.13 & & -0.03 & & -0.05 & & 0.19 & * \\
\hline \multicolumn{11}{|c|}{ Children born in the country of origin (Ref.: Not existent) } & & \\
\hline Existent & & & 0.31 & $* * *$ & & & & & & & 0.33 & $* * *$ \\
\hline \multicolumn{13}{|c|}{$\begin{array}{l}\text { Own nationality / nationality of the partner (Ref.: Non-German / non-German) } \\
\text { Non-German / }\end{array}$} \\
\hline German & & & -0.09 & $*$ & & & & & & & -0.06 & \\
\hline \multicolumn{13}{|c|}{ Years of school attendance (Ref.: 9 - 12 years) } \\
\hline$<9$ years & & & & & 0.13 & $* *$ & & & & & 0.05 & \\
\hline$>12$ years & & & & & -0.01 & & & & & & -0.04 & \\
\hline \multicolumn{13}{|c|}{ Training qualification (Ref.: Completed apprenticeship) } \\
\hline None & & & & & 0.08 & + & & & & & 0.05 & \\
\hline Other, higher & & & & & 0.00 & & & & & & 0.01 & \\
\hline \multicolumn{13}{|c|}{ Religious affiliation (Ref.: Catholic) } \\
\hline Christian Orth & & & & & & & 0.07 & & & & 0.06 & \\
\hline Muslim & & & & & & & 0.43 & $* * *$ & & & 0.33 & $* * *$ \\
\hline Others, none & & & & & & & 0.05 & $*$ & & & 0.07 & + \\
\hline \multicolumn{11}{|c|}{ Self-evaluated religiosity (Ref.: Little, not religious) } & & \\
\hline (Very) religiou & & & & & & & 0.10 & * & & & 0.03 & \\
\hline Neutral & & & & & & & 0.05 & & & & 0.03 & \\
\hline \multicolumn{11}{|c|}{ Emotional ties to the country of origin (Ref.: Neutral) } & & \\
\hline Very strong & & & & & & & & & 0.05 & & -0.02 & \\
\hline Strong & & & & & & & & & 0.07 & + & 0.02 & \\
\hline Little, none & & & & & & & & & 0.06 & + & -0.01 & \\
\hline \multicolumn{11}{|c|}{ Emotional ties to Germany (Ref.: Neutral) } & & \\
\hline Very strong & & & & & & & & & 0.02 & & 0.08 & + \\
\hline Strong & & & & & & & & & 0.02 & & 0.00 & \\
\hline Little, none & & & & & & & & & -0.01 & & 0.02 & \\
\hline \multicolumn{11}{|c|}{ Native language skills (Ref.: Good) } & & \\
\hline Very good & & & & & & & & & -0.04 & & 0.01 & \\
\hline Medium, none & & & & & & & & & 0.10 & $* *$ & 0.03 & \\
\hline \multicolumn{11}{|c|}{ German language skills (Ref.: Good) } & & \\
\hline Very good & & & & & & & & & -0.06 & + & -0.02 & \\
\hline Medium, none & & & & & & & & & 0.08 & + & 0.02 & \\
\hline Total (n) & 864 & & 671 & & 792 & & 854 & & 864 & & 610 & \\
\hline $\mathbf{R}^{2}$ & 0.221 & & 0.300 & & 0.212 & & 0.259 & & 0.254 & & 0.319 & \\
\hline
\end{tabular}

Note: *Only women over age 40 are considered.

Significance of the beta coefficient: $* * *=p<0,001 ; * *=p<0,01 ; *=p<0,05 ;+=p<0,10$.

Source: Authors' calculations based on the RAM 2006/2007, unweighted. 
Table 5:

Fertility of migrant women* in Germany by country of origin, results from a multiple regression model (block-wise)

\begin{tabular}{|c|c|c|c|c|c|c|c|c|c|c|c|}
\hline & Turkey & \multicolumn{2}{|c|}{$\begin{array}{c}\text { Former } \\
\text { Yugoslavia }\end{array}$} & \multicolumn{2}{|c|}{ Italy } & \multicolumn{2}{|c|}{ Greece } & \multicolumn{2}{|c|}{ Poland } & \multicolumn{2}{|c|}{ All } \\
\hline & Beta Sig. & Beta & Sig. & Beta & Sig. & Beta & Sig. & Beta & Sig. & Beta & Sig. \\
\hline \multicolumn{12}{|c|}{ Birth Cohort (Ref.: 1940 and older) } \\
\hline $1941-1950$ & 0.17 & 0.04 & & 0.28 & & -0.09 & & 0.15 & & 0.07 & \\
\hline $1951-1960$ & 0.06 & 0.01 & & 0.41 & + & 0.22 & & 0.38 & & 0.04 & \\
\hline $1961-1965$ & 0.19 & -0.10 & & 0.24 & & 0.28 & & 0.31 & & 0.04 & * \\
\hline \multicolumn{12}{|c|}{ Length of stay (Ref.: Less than 10 years) } \\
\hline $10-20$ years & 0.06 & 0.23 & & 0.01 & & -0.35 & & -0.10 & & 0.02 & \\
\hline $20-30$ years & $0.33+$ & 0.26 & * & 0.07 & & -0.08 & & -0.13 & & 0.16 & * \\
\hline$>30$ years & 0.30 & 0.30 & & 0.25 & & 0.11 & & 0.30 & & 0.19 & * \\
\hline \multicolumn{12}{|c|}{ Children born in the country of origin (Ref.: Not existent) } \\
\hline Existent & $0.34 * * *$ & 0.35 & $* * *$ & 0.31 & $*$ & 0.43 & $*$ & 0.48 & $*$ & 0.33 & $* * *$ \\
\hline \multicolumn{12}{|c|}{ Own nationality / nationality of the partner (Ref.: Non-German / non-German) } \\
\hline German & 0.01 & -0.14 & + & 0.01 & & -0.18 & & 0.19 & & -0.06 & \\
\hline \multicolumn{12}{|c|}{ Years of school attendance (Ref.: 9 -12 years) } \\
\hline$<9$ years & -0.02 & 0.12 & & -0.03 & & -0.30 & & 0.19 & & 0.05 & \\
\hline$>12$ years & 0.02 & -0.05 & & -0.11 & & -0.07 & & 0.01 & & -0.04 & \\
\hline \multicolumn{12}{|c|}{ Training qualification (Ref.: Completed apprenticeship) } \\
\hline None & -0.03 & 0.05 & & 0.11 & & 0.13 & & 0.06 & & 0.05 & \\
\hline Other, higher & -0.07 & 0.03 & & 0.02 & & 0.01 & & 0.21 & & 0.01 & \\
\hline \multicolumn{12}{|c|}{ Religious affiliation (Ref.: Catholic) } \\
\hline Christian Orthodox & & 0.09 & & & & & & & & 0.06 & \\
\hline Muslim & & 0.28 & $* *$ & & & & & & & 0.33 & $* * *$ \\
\hline Others, none & & 0.03 & & & & & & & & 0.07 & + \\
\hline \multicolumn{12}{|c|}{ Self-evaluated religiosity (Ref.: Little, not religious) } \\
\hline (Very) religious & 0.02 & 0.01 & & -0.02 & & 0.04 & & -0.22 & & 0.03 & \\
\hline Neutral & 0.11 & -0.09 & & 0.10 & & 0.10 & & -0.22 & & 0.03 & \\
\hline \multicolumn{12}{|c|}{ Emotional ties to the country of origin (Ref.: Neutral) } \\
\hline Very strong & 0.04 & -0.10 & & 0.04 & & -0.14 & & -0.02 & & -0.02 & \\
\hline Strong & 0.10 & 0.01 & & -0.05 & & -0.12 & & 0.05 & & 0.02 & \\
\hline Little, none & 0.05 & -0.14 & & 0.25 & * & 0.06 & & 0.01 & & -0.01 & \\
\hline \multicolumn{12}{|c|}{ Emotional ties to Germany (Ref.: Neutral) } \\
\hline Very strong & -0.03 & 0.31 & $* *$ & -0.10 & & -0.05 & & 0.18 & & 0.08 & + \\
\hline Strong & -0.02 & 0.08 & & -0.09 & & 0.01 & & 0.05 & & 0.00 & \\
\hline Little, none & 0.05 & 0.02 & & -0.18 & + & -0.13 & & -0.17 & & 0.02 & \\
\hline \multicolumn{12}{|c|}{ Native language skills (Ref.: Good) } \\
\hline Very good & 0.11 & -0.07 & & -0.14 & & 0.01 & & -0.27 & & 0.01 & \\
\hline Medium, none & $0.13+$ & 0.03 & & -0.28 & $*$ & -0.13 & & 0.00 & & 0.03 & \\
\hline \multicolumn{12}{|c|}{ German language skills (Ref.: Good) } \\
\hline Very good & -0.14 & 0.08 & & -0.17 & & -0.10 & & 0.19 & & -0.02 & \\
\hline Medium, none & 0.03 & 0.04 & & 0.11 & & 0.16 & & 0.06 & & 0.02 & \\
\hline Total (n) & 172 & 147 & & 104 & & 98 & & 89 & & 610 & \\
\hline $\mathbf{R}^{2}$ & 0.203 & 0.336 & & 0.467 & & 0.391 & & 0.519 & & 0.319 & \\
\hline
\end{tabular}

Note: *Only women over age 40 are considered.

Significance of the beta coefficient: $* * *=p<0,001 ; * *=p<0,01 ; *=p<0,05 ;+=p<0,10$.

Source: Authors' calculations based on RAM 2006/2007, unweighted. 


\section{Conclusion}

Studies of the reproductive behaviour of female migrants in Germany came to the conclusion that the usually higher fertility norms of migrants' country of origin will not be maintained in Germany. This may be due to a post-migratory adaptation process into the lowest-low fertility situation which Germany has been displaying for decades: the conditions of living, working and housing inevitably support together a 'regime' of small family size and slightly growing childlessness. But this generally observed fertility decline turns out to be a multifaceted picture when single national and ethnic migrant groups are examined. The fertility level of the country of origin and migrants' social and family background are a source of considerable differences concerning the downward movement of fertility after immigration.

The RAM 2006/2007 survey with its representative coverage of five major migrant groups of women (from Turkey, former Yugoslavia, Italy, Greece, Poland) offers data on numerous variables and is therefore well-suited for an empirical analysis of fertility behaviour of female migrants in Germany.

Empirical analyses based on the RAM survey show that the completed fertility of female migrant groups is very heterogeneous: migrant women coming from Turkey display the highest CFR while women from Poland have the lowest fertility. Childlessness of Turkish women is very rare, whereas it is more common among women coming from Poland and former Yugoslavia. Turkish migrant women realise their desire for offspring earlier than migrant women coming from former Yugoslavia, Italy, Greece and Poland. Additionally, it was found that migrant women with German partners have a lower fertility. Arguably, a migrant woman married to a German husband gets more intensive contact with the mainstream German society, which will promote her adaptation to German low fertility norms and values.

These results confirm the expected paths of reproductive behaviour which is in tune with the adaptation hypothesis. In contrast, the higher fertility of Polish women who mostly entered Germany for marriage is a phenomenon signalling a greater family orientation of this migrant group. This points to the selection hypothesis and the higher motivation for parenthood when migration and family formation are linked (interrelation hypothesis). A selection hypothesis receives further support from the link between higher education and lower fertility among migrant women.

Furthermore, the reproductive behaviour of Muslim women is partly determined both by their affiliation and religiosity level; mostly reflecting their socialisation experiences in the country of origin (socialisation hypothesis). The fertility of migrant women declines with an increasing level of integration in Germany. Emotional ties with the country of origin and the level of native language skills show no signs of influencing the fertility of female migrants; this 
finding runs contrary to the socialisation hypothesis and gives a greater prominence to the adaptation hypothesis.

Due to the data in use, unfortunately we could not consider persons of migrant origin. Neither could we differentiate between first and second-generation migrants. Our analyses can provide indications of the links between migration and fertility but do not yield strong empirical evidence. We can sum up that further research is needed. Particularly the empirical testing of the hypotheses on migrant fertility would be crucial for advancing our understanding of whether and how migration influences the reproductive behaviour of migrant women.

Furthermore we need better knowledge about the effects of migrant fertility on future population development in Germany, because the juvenile cohorts show an increasing share of children of foreign-born mothers.

\section{Acknowledgments}

The authors gratefully thank for the helpful comments from anonymous reviewers and the support from the editors.

\section{References}

Abbasi-Shavazi, M. J. and P. McDonald. 2002. "A comparison of fertility patterns of European immigrants in Australia with those in the countries of origin." Genus 58(1): 53-76.

Andersson, G. 2004. "Childbearing after migration: fertility patterns of foreign-born women in Sweden." International Migration Review 38(2): 747-774.

Babka von Gostomski, C. 2008. Türkische, griechische, italienische and polnische Personen sowie Personen aus den Nachfolgestaaten des ehemaligen Jugoslawien in Deutschland. Nürnberg, Federal Office for Migration and Refugees.

Babka von Gostomski, C. and M. Pupeter. 2008. "Zufallsbefragung von Ausländern auf Basis des Ausländerzentralregisters. Erfahrungen bei der Repräsentativbefragung 'Ausgewählte Migrantengruppen in Deutschland 2006/2007' (RAM).' Methoden Daten - Analysen. Zeitschrift für empirische Sozialforschung 2: 149-177.

Brockeroff, M. 1995. "Fertility and family-planning in African cities: the impact of female migration." Journal of Biosocial Science 27(3): 347-358.

Brockeroff, M. and X. S. Yang. 1994. "Impact of migration on fertility in Sub-Saharan Africa." Social Biology 41: 19-43.

Carlson, E. D. 1985. "The impact of international migration upon the timing of marriage and childbearing." Demography 22: 61-72.

Coleman, D. 2006. "Immigration and ethnic change in low-fertility countries: a third demographic transition?" Population and Development Review 23(3): 401-446.

Courgeau, D. 1989. "Family formation and urbanization." Population: An English Selection 44: 123-146. 
Dinkel, R. H. 1990. "Der Einfluss von Wanderungen auf die langfristige Bevölkerungsdynamik.” Acta Demographica 1: 47-62.

Dinkel, R. H. and U. H. Lebok. 1997. "The fertility of migrants before and after crossing the border." International Migration 35(2): 253-270.

Duncan, O. D. 1965. "Farm background and differential fertility." Demography 2: 240-249.

Esser, H. 1980. Aspekte der Wanderungssoziologie. Darmstadt/Neuwied, Hermann Luchterhand Verlag GmbH.

Ette, A., G. Hullen, I. Leven, and K. Ruckdeschel. 2007. "Generations and Gender Survey. Dokumentation der Befragung von türkischen Migranten in Deutschland." Materialien zur Bevölkerungswissenschaft, 121b. Wiesbaden, Bundesinstitut für Bevölkerungsforschung.

Farber, S. C. and B. S. Lee. 1984. "Fertility adaptation of rural-to-urban migrant women: a method of estimation applied to Korean women." Demography 21: 339-345.

Freedman, R. and D. P. Slesinger. 1961. "Fertility differentials for the indigenous nonfarm population of the United States." Population Studies 15: 161-173.

Genereux, A. 2007. "A review of migration and fertility through the lens of African immigrant fertility in France." MPIDR Working paper WP 2007-008.

German Federal Ministry of the Interior. 2008. Definition of "Persons of migrant origin". Accessed from: «http://www.zuwanderung.de/nn_1120100/EN/ImmigrationToday/ ImmigrationAZ/Functions/AZ_catalog,lv2=1123182,lv3=1085870.html».

German Federal Statistical Office. 2007. Geburten in Deutschland. Wiesbaden, German Federal Statistical Office.

German Federal Statistical Office. 2008. Fachserie 1, Reihe 2.2. Bevölkerung und Erwerbstätigkeit. Bevölkerung mit Migrationshintergrund, Ergebnisse des Mikrozensus 2007. Wiesbaden, German Federal Statistical Office.

German Federal Statistical Office. 2009. Fachserie 1, Reihe 2. Bevölkerung und Erwerbstätigkeit. Ausländische Bevölkerung. Ergebnisse des Ausländerzentralregisters. Wiesbaden, German Federal Statistical Office.

Goldberg, D. 1959. "The fertility of two-generation urbanities." Population Studies 12: 214-222.

Goldstein, S. 1973. "Interrelations between migration and fertility in Thailand." Demography 10: 225-241.

Goldstein, S. and A. Goldstein. 1981. "The impact of migration on fertility: an 'own children' analysis for Thailand.” Population Studies 35: 265-281.

Haug, S. 2002. "Familie, soziales Kapital und soziale Integration. Zur Erklärung ethnischer Unterschiede in Partnerwahl und generativem Verhalten bei jungen Erwachsenen deutscher, italienischer und türkischer Abstammung." Zeitschrift für Bevölkerungswissenschaft 27(4): 393-425.

Hervitz, H. M. 1985. "Selectivity, adaptation, or disruption? A comparison of alternative hypotheses on the effects of migration on fertility: the case of Brazil." International Migration Review 19: 293-317.

Höhn, C., U. Mammey, and H. Wendt. 1990. "Bericht 1990 zur demographischen Lage: Trends in beiden Teilen Deutschlands und Ausländer in der Bundesrepublik Deutschland." Zeitschrift für Bevölkerungswissenschaft 16: 135-205.

Hoem, J. M. 1975. "Fertility and out-migration: reflections on research approaches in empirical investigations of the association between two demographic phenomena." 
Working Paper 1. University of Copenhagen, Laboratory of Actuarial Mathematics: Copenhagen.

Huinink, J. 1995. "Familienentwicklung und Haushaltsgründung in der DDR: Vom traditionellen Muster zur instrumentellen Lebensplanung?” In: B. Nauck et al. (eds.) Familie und Lebensverlauf im gesellschaftlichen Umbruch. Stuttgart, Enke, pp. 39-55.

Kahn, J. R. 1988. "Immigrant selectivity and fertility adaptation in the U.S." Social Forces 67: 108-128.

Kahn, J. R. 1994. "Immigrant and native fertility during the 1980s: adaptation and expectations for the future." International Migration Review 28: 501-519.

Kane, T. T. 1986. "The fertility and assimilation of guestworker populations in the Federal Republic of Germany: 1961-1981.” Zeitschrift für Bevölkerungswissenschaft 12(1): 99-131.

Klein, T. and W. Lauterbach. 1994. "Bildungseinflüsse auf Heirat, die Geburt des ersten Kindes und die Erwerbsunterbrechung von Frauen." Kölner Zeitschrift für Soziologie und Sozialpsychologie 46(2): 278-298.

Kohls, M. 2007. "Mobilität der Jugend in globaler Perspektive.” In: D. Villanyi, M. Witte, and U. Sander (eds.) Globale Jugend und Jugendkulturen - Aufwachsen im Zeitalter der Globalisierung. Weinheim, Juventa-Verlag, pp. 113-126.

Kohls, M. 2008. Erfassungsfehler, Healthy-Migrant-Effect und andere Schwierigkeiten bei der Analyse der Mortalität von Migranten. Eine Bestandsaufnahme. Nürnberg, Bundesamt für Migration und Flüchtlinge.

Kreyenfeld, M. 2004: "Fertility decisions in the FRG and GDR: an analysis with data from the German Fertility and Family Survey." Demographic Research S3(11): 276-318.

Kreyenfeld, M. and T. Mika. 2006: “Analysemöglichkeiten der Biografiedaten des 'Scientific Use Files VVL 2004' im Bereich Fertilität und Familie." Deutsche Rentenversicherung (ed.). Bad Homburg, WDV, 9-10, 583-608.

Konietzka, D. and M. Kreyenfeld. 2007. Ein Leben ohne Kinder: Kinderlosigkeit in Deutschland. Wiesbaden, VS Verlag für Sozialwissenschaften.

Kulu, H. 2005. "Migration and fertility: competing hypotheses re-examined." European Journal of Population 21(1): 51-87.

Lee, B. S. and L. G. Pol. 1993. "The influence of rural-urban migration on migrants fertility in Korea, Mexico and Cameroon." Population Research and Policy Review 12: 3-26.

Lindstrom, D. P. and S. Giorguli-Saucedo. 2007. "The interrelationship of fertility, family maintenance, and Mexico-U.S. Migration.” Demographic Research 17(28): 821-858.

Macisco, J., L. F. Bouvier, and R. H. Weller 1970. "The effect of labour force participation on the relation between migration status and fertility in San Juan, Puerto Rico.” Milbank Memorial Fund Quarterly 48: 51-70.

Mammey, U. 1990. "35 Jahre Ausländer in der Bundesrepublik Deutschland - die demographische Entwicklung." In: C. Höhn and D. B. Rein (eds.) Ausländer in der Bundesrepublik Deutschland. Boppard am Rhein, Boldt, pp. 55-82.

Mammey, U. and K. Schwarz 2002. "The demographic characteristics of the immigrant population in Germany". In: W. Haug, P. Compton, and Y. Courbage (eds.) The demographic characteristics of immigrant populations. Population Studies No. 38: 193-244.

Mayer, J. and R. T. Riphahn. 2000. "Fertility assimilation of immigrants: Evidence from count data models." Journal of Population Economics 13: 241-261. 
Michielin, F. 2004. "Lowest low fertility in an urban context: the role of migration in Turin, Italy." Population, Space and Place 10: 331-347.

Milewski, N. 2007. "First child of immigrant workers and their descendants in West Germany: Interrelation of events, disruption, or adaptation?" Demographic Research 17(29): 859-896.

Milewski, N. 2008. Fertility of Immigrants and Their Descendants in West Germany - An Event-history Approach. Doctoral thesis. Rostock, Max-Planck Institute for Demographic Reseach.

Mulder, C. H. and M. Wagner. 1993. "Migration and marriage in the life course: a method for studying synchronized events." European Journal of Population 9: 55-76.

Myers, G. C. and E. W. Morris. 1966. "Migration and fertility in Puerto Rico." Population Studies 20: 85-96.

Nauck, B. 1987. "Individuelle und kontextuelle Faktoren der Kinderzahl in türkischen Migrantenfamilien.” Zeitschrift für Bevölkerungswissenschaft 13(3): 319-344.

Nauck, B. 1988. "Dreißig Jahre Migrantenfamilien in der Bundesrepublik. Familiärer Wandel zwischen Situationsanpassung, Akkulturation, Segregation und Remigration." In: R. Nave-Herz (ed.) Wandel und Kontinuität der Familie in der Bundesrepublik Deutschland. Stuttgart, Enke, pp. 315-339.

Nauck, B. 1993. "Bildung, Migration und generatives Verhalten bei türkischen Frauen." In: A. Diekmann and S. Weick. Der Familienzyklus als sozialer Prozess. Berlin, Duncker \& Humboldt, pp. 309-346.

Nauck, B. 2007. "Migrantenfamilien in Deutschland. Familiärer Wandel zwischen Situationsanpassung, Akkulturation, Segregation und Remigration." Zeitschrift für Familienforschung 19(1): 34-54.

Peuckert, R. 2008. Familienformen im sozialen Wandel. Wiesbaden, Vs Verlag für Sozialwissenschaften.

Roloff, J. 1997. "Die ausländische und deutsche Bevölkerung in der Bundesrepublik Deutschland - ein bevölkerungsstatistischer Vergleich." Zeitschrift für Bevölkerungswissenschaft 22(1): 73-98.

Rosenwaike, I. 1973. "Two generations of Italians in America: their fertility experience." International Migration Review 7: 271-280.

Ruckdeschel, K., A. Ette, G. Hullen, and I. Leven. 2006. "Generations and Gender Survey. Dokumentation der ersten Welle der Hauptbefragung in Deutschland." Materialien zur Bevölkerungswissenschaft 121, Wiesbaden, Bundesinstitut für Bevölkerungsforschung.

Scholz, R. 2005. "Differenzielle Sterblichkeit in der GRV. Problemaufriss und erste Berechnungen." DRV-Schriften 55: 253-266.

Schoorl, J. 1995. "Fertility trends of immigrant populations." In: S. Voets, J. Schoorl, and B. Brujin (eds.) Demographic consequences of international migration. NIDI-Report 44: 97-122.

Schmid, S. and M. Kohls. 2008. "Sind die FDZ-RV Daten für eine Analyse des generativen Verhaltens von Migrantinnen geeignet?” DRV-Schriften 55: 121-143.

Schmid, S. and M. Kohls. 2009. Beeinflusst Migration das generative Verhalten. Eine Bestandsaufnahme des generativen Verhaltens von Migrantinnen in Deutschland. Nürnberg: Bundesamt für Migration und Flüchtlinge (forthcoming).

Schulz, R. 1978. "Die Entwicklung der Fruchtbarkeit ausländischer Staatsangehöriger im Deutschen Reich bzw. der Bundesrepublik Deutschland." Materialien zur Bevölkerungswissenschaft 7, Wiesbaden, Bundesinstitut für Bevölkerungsforschung. 
Schwarz, K. 1980. "Demographische Charakteristika der Türken in der Bundesrepublik Deutschland." Zeitschrift für Bevölkerungswissenschaft 6: 411-420.

Schwarz, K. 1996. "Die Kinderzahl der Ausländer und ihre Bedeutung für die Bevölkerungsentwicklung in den alten Bundesländern." Zeitschrift für Bevölkerungswissenschaft 21(1): 57-67.

Singley, S. G. and N. S. Landale. 1998. "Incorporating origin and process in migrationfertility frameworks: the case of Puerto Rican women." Social Forces 76: 1437-1464.

Sobotka, T. 2008. "Overview chapter 7: The rising importance of migrants for childbearing in Europe." Demographic Research 19: 225-248.

Stephen, E. H. and F. D. Bean. 1992. "Assimilation, Disruption and the fertility of Mexican-Origin Women in the United States." International Migration Review 26(1): 67-88.

UN. 2000. Replacement Migration: Is it a Solution to Declining and Ageing Populations? New York, United Nations. Population Division, ESA/P/WP.160.

Westoff, C. and T. Frejka. 2007. "Religiousness and fertility among European Muslims." Population and Development Review 33(4): 785-809.

White, M., L. Moreno, and S. Guo. 1995. "The interrelation of fertility and geographic mobility in Peru: a hazards model analysis." International Migration Review 29: 492-514.

Young, C. M. 1991. "Changes in the demographic behavior of migrants in Australia and the transition between generations." Population Studies 45: 67-89. 

